\title{
Over-Issued Currency and Real Estate Asset Prices in China Market
}

\author{
Wu Mingze ${ }^{1}$ \\ ${ }^{1}$ School of economics and management, Shandong University of science and technology, \\ Qingdao,Shandong266590, China \\ Email: wumingze1999@163.com
}

\begin{abstract}
In the context of excessive currency issuance, the growth rate of real estate (hereinafter referred to as "RE") and land prices is generally lower than the growth rate of broad money, while the growth rate of RE in first-tier cities is basically the same. On the one hand, China's RE is a comprehensive value body that bundles a variety of resources, including household registration, school districts, hospitals, etc., which to a certain extent reflects the price level of items that are difficult to quantify. On the other hand, RE has strong financial attributes of value preservation and appreciation. It is one of the important asset pools that absorb over-issue currency. The combined effect of the two factors made China's RE prices rise rapidly in the past. From a long-term perspective, the policy of ignoring over-issuance of currency is of little significance to the Chinese economy in transition. On the contrary, it delays the adjustment of economic structure and the transformation of growth mode, and is not beneficial to long-term economic growth.
\end{abstract}

Keywords: over-issued currency, real estate asset, asset prices, growth rate

\section{INTRODUCTION}

The creation of credit currency in China is mainly derived from various loan derivations, commercial bank securities net investment, foreign exchange funds, financial industry inter-bank derivations, and other items including fiscal deposits and gold funds. Looking back on the history of currency issuance in China, it can be divided into five historical stages according to the main sources of credit creation:

The first stage (1987-2000) is the initial stage of commercial bank development. The use of bank funds has developed from single to gradual diversification. During this period, M2 is mainly derived from various types of loans, and foreign exchange accounts gradually increase.

The second stage (2001-2008) is the era of rapid increase in foreign exchange funds. China's accession to the WTO, expansion of reform and opening up, and rapid increase in international trade activities, foreign exchange funds have become the main means and means of central bank currency investment. Co-creation of various loans and foreign exchange funds.

The third stage (2009-2010) is a period of rapid loan expansion. After the subprime mortgage crisis, the world economy is in recession, and the driving effect of external demand on the economy has weakened. Under the influence of stimulating macroeconomic policies, China's credit supply has continued to grow rapidly, and various types of loans have once again become the main source of money creation.

The fourth stage (2011-2016) is a period of rapid rise in the industry and a period of decline in foreign exchange holdings. The expected depreciation of the renminbi has increased, capital outflows have been serious, and the stock of foreign exchange holdings has declined. At this stage, loans and interbanks are the main sources of currency creation.

The fifth stage (2017-present) is the return of interbank shrinking and foreign exchange policies to a neutral period. Due to the early stage, major financial risks were prevented and controlled, strict supervision, and supervision of capital inflows into physical enterprises, emphasizing the removal of funds from virtual and real, inter-bank business has shrunk sharply.

From the historical process of currency issuance in China, it can be seen that various loans have always been the main force in the creation of currency. Changes in the internal and external environment and policies in 
different periods have led to changes in the secondary driving force for currency issuance.

Since 2008, the extent, breadth and depth of currency over-issuance have far exceeded the previous level. During the period from 2008 to 2017 , all indicators showed that China's currency over-issuance increased significantly, with an average annual nominal currency gap of nearly 50 billion, an increase of $4,300 \%$ from the average of 2000-2007, and the currency excess rate and broad credit growth rate reached $4.8 \%$ and $21.6 \%$. In addition, the currency over-issuance rate basically exceeded the highest level. In 2009, the degree of currency oversupply was the largest. The year-on-year growth rates of broad credit and M2 reached $45.6 \%$ and $28 \%$ respectively, and the nominal currency gap reached an astonishing 1,68581 billion yuan, a new high since the founding of the country.

Indicators starting from money supply and money demand show that China has had a serious currency oversupply in the past eighteen years, especially in the past ten years after 2008, and M2 broad money has also quadrupled from 40 trillion to 1.67 million. During this period, the GDP has risen less than doubled, and the increase in urban residents' income and national housing prices are far lower than the M2 expansion. Excessive currency eventually flows into the physical market and the financial market represented by RE, which is an important reason for the external rise and internal depreciation of the RMB.

\section{LITERATURE REVIEW}

Jansen (2013) used the VAR model to empirically study the relationship between RE prices and RE credit in Norway from 1986 to 2008. The results show that, from a long-term perspective, there is a significant twoway relationship between RE prices and credit. Rising market prices will promote the expansion of credit scale. Conversely, the expansion of credit loan scale will also promote the rise of RE prices, but from a short-term perspective, this two-way relationship is not significant. [1]

Liu Chuanzhe and Nie Xuefeng (2005) used a variety of methods to analyze the relationship between China's relevant monetary policy and RE prices, and concluded that the effect of monetary policy changes on housing prices is greater than the effect of interest rate changes on housing prices. [2]

Yuan Hui and Ma Zhefeng (2008) constructed a VAR model. Using this model, a total of 38 sets of relevant quarterly data in China from 1999 to 2008 were studied. The study found that China's RE prices, money supply, land prices and The gross domestic product shows a significant positive correlation. [3]

Hong Bo and Luo Xiaoling (2012) established a VAR model based on the relevant data from 2001 to 2010 in
China. Through different analysis methods such as variance analysis and impulse response function methods, they deeply studied the time lag of different factors, and found that housing prices are different from domestic prices. There is a two-way Granger causality between GDP and money supply. Compared with GDP, money supply has a greater impact on housing prices. [4]

Wen Chujiang (2013) selected China's monthly data from January 2001 to December 2011, and built a VAR model to deeply study the money supply at different levels, and to determine its impact on RE prices. Contrast. According to the results, M0, M1, and M2 all have positive effects on RE prices, and M2 has the smallest effect on RE prices among the three. [5]

Miao Qing (2018) conducted an in-depth study on China's money supply and housing prices from February 2000 to December 2017 through the establishment of a VAR model, and found that there is a significant positive correlation between the two. The government should strictly control the level of money supply and its growth rate in the process of formulating and implementing policies, so as to prevent excessive RE prices from rising. [6]

Yuan Qingqing (2018) collected relevant quarterly data from 1998 to 2017 in China, and established a VAR model between China's RE sales price and money supply M2. At the same time, the national economy's GDP, RE investment scale and residents' average Control variables such as income are included. Research is conducted using correlation analysis methods, impulse response function research, and Johanson coordination relationship research. It is concluded that there is a longterm stable equilibrium relationship between RE prices and money supply. The former can have a positive effect. There is a quarterly time difference between the two. Compared with quasi-money, the broad money supply can have a significant impact on RE prices. [7] Liang Yunfang and Gaotiemei (2007) used panel data analysis model to analyze the regional differences of RE prices in China. [8]

$\mathrm{Xu}$ Xiaotong (2018) first explained the relationship between China's RE prices and bank credit loans theoretically, and then used VAR modeling analysis to conduct empirical analysis on the average price of commercial housing and the scale of bank loans in China from 2003 to 2004. The results show that the expansion of bank credit promotes the increase in market prices of commercial housing, showing a positive correlation. [9]

Liang Qi (2018) is based on China's stock prices, housing prices, money supply, bank credit volume, loan interest rates and their first-order difference data from January 2018 to February 2017. By means of sequence analysis, a vector autoregressive model was constructed. Through research, it is found that first, China's money supply, financial institution credit level and loan theory 
have a long-term coordinated and stable relationship with housing prices (commercial housing and residential housing), which also allows China to formulate a currency that regulates housing prices. [10]

Zhang Xiekui and Dai Xiaoling (2018) established a VAR model and used relevant data from 2003 to 2016 to study China's housing prices and financial risks. The results show that in the short term, rising housing prices will increase credit risk. In the long run, there is a cointegration relationship and two-way Granger causality between the two. [11]

\section{WHETHER RE CAN OUTPERFORM CURRENCY OVER-ISSUANCE}

Although the issuance of excess currency stimulated economic growth on the one hand, it also caused a decline in the purchasing power of the currency and the domestic devaluation of the RMB. We have conducted statistical calculations on the prices of major assets such as stocks, bonds, and commodities, as well as some of the prices of commodities and non-commodity markets represented by Beijing from the reform and opening up to 2017, and found that the prices of various commodities and major assets and currencies exceed the relationship between issuance can be divided into three categories: one is that the price increase is much lower than the growth rate of currency, and the currency is underperformed. This is reflected in various physical commodities, fixed-income bonds and bulk commodities; currency growth rates are not much different or basically the same. Service products such as healthcare and education, as well as land and RE in firsttier cities reflect this; third, prices have increased substantially in the past and outperformed currency oversupply. After 2009, stocks have reflected this. a little.

The upgrade promotes the rise in housing demand, which reflects the commodity attributes of RE; and the other part is that the speculative demand caused by the oversupply of currency and the monopoly of land supply leads to the rapid rise of housing prices, which reflects the financial attributes of RE. In the short term, financial factors such as currency oversupply and lower loan interest rates have a significant stimulus effect on housing prices. From 2005 to 2017, M1, M2 and loan interest rates are significantly correlated with housing prices. The rise in M1, M2 and the decline in loan interest rates are all accompanied by housing prices.

\section{CONCLUSION}

We compare the RE prices in first-tier cities with the performance of other various assets under the currency over-issuance.

Looking back at the history of China's currency issuance in the past 40 years, currency liquidity has been in excess for most of the period. This round of currency liquidity has been in excess for a long time after the severe surplus in 2009. For a long time, currency "passivation" has made loose money affect the real economy. The promotion effect is getting smaller and smaller, and the impact on the price of broad assets has increased significantly, and the degree of differentiation of various commodities and assets has further deepened.

1) Commodities and fixed-income bonds underperform currency growth. In the long run, stock volatility will greatly affect their compound growth rate and outperform currency overissues in the medium term. The yields of commodities and fixed-income bonds have been significantly lower than the growth rate of broad money in the past 40 years, which is related to their nature as safe-haven assets. Although the prices of commodities and bonds may fluctuate greatly in the short term, in the long term, the volatility is low, and the risk premium required for compensation is relatively small. The difference between the overall rate of return and the growth rate of broad money tends to expand in the longterm monetary easing range.

From the perspective of stocks, generally speaking, the average annual compound yield of stocks during the period of currency over-issuance from 2000 to 2017 outperformed commodities and fixed-income bonds, but the overall yield has not yet outperformed currency overissuance. At the same time, due to the high risk and high volatility of stocks, the compound rate of return is easily affected by the selected time interval. From a mediumterm perspective, during the currency over-issuance period, the stock compound return rate can basically outperform the currency over-issuance period, and small and medium-cap stocks are more susceptible to changes in economic fundamentals and monetary policy due to the cash flow and balance sheet of entities. The overall yield volatility is greater than that of the broader market index.

2) In the context of excessive currency issuance, the growth rate of RE and land prices is generally lower than that of broad money, while the growth rate of RE in firsttier cities is basically the same. On the one hand, China's $\mathrm{RE}$ is a comprehensive value body that bundles a variety of resources, including household registration, school districts, hospitals, etc., which to a certain extent reflects the price level of items that are difficult to quantify. On the other hand, RE has strong financial attributes of value preservation and appreciation. It is one of the important asset pools that absorb over-issue currency. The combined effect of the two factors has made China's RE prices rise rapidly in the past.

In addition, according to our analysis framework of looking at population in the long-term, land in the medium-term, and financial in the short-term, compared with second-, third-, and fourth-tier cities, long-term population inflows, industrial introductions, and 
consumer consumption upgrades in first-tier cities have increased housing demand, and land supply in the medium-term monopoly, RE prices have an inherent motivation for natural appreciation, and they are more sensitive to currency oversupply in the short term. The stimulus of currency over-issuance has led to a rapid increase in first-tier housing prices, leading to the same level of growth in land prices and house compound growth in first-tier cities, and basically the same as currency growth. However, population outflow and relatively sufficient land supply in second, third and fourth-tier cities serve as cushions, making RE. The premium is relatively limited, and RE prices vary significantly across regions.

3) The price growth rate of traditional physical commodities is gradually out of line with the currency oversupply, and the price growth rate of products such as medical care and education services with rigid demand has a small gap with the broad money growth rate. The currency oversupply has a strong impact on core prices. Although it is not rigorous to use the prices of some products in the Beijing commodity market as the basis for inference, the law of price increases reflected from it is still instructive. At present, China's commodities are mainly composed of general competitive products and monopolistic or demand-rigid products, and the two are different in sensitivity to currency oversupply. The historical data of the Beijing commodity market shows that traditional food, tobacco, alcohol, light textile industrial products and other commodities have limited price compound growth after the reform and opening up. This is mainly due to the technological advancement of such commodities, large-scale production, and sufficient internal and external market competition, which have led to more substitutes. related. From the perspective of products and services with monopolistic nature or rigid demand, represented by medical care and education services, the main problem they face is "supply constraints." When currency is over-issued, it is easy to cause too much currency to chase limited products. This leads to continuous price increases.

4) From a long-term perspective, the policy of ignoring over-issuance of currency is of little significance to the Chinese economy in transition. On the contrary, it delays the adjustment of economic structure and the transformation of growth mode, and is not beneficial to the long-term economic growth. Regardless of whether it is from the international experience of Europe, America and Japan, or from the actual experience of China in the past, the over-issuance of currency has limited promotion of the real economy in the growth shift. In the long run, excess funds will eventually have a "passivation" effect, which will flow into the capital market, causing funds to become virtual and destructive, which will damage the real economy. Only through unswerving opening up, deregulation of the industry, reducing tax burdens, reforming state- owned enterprises, encouraging innovation and other new rounds of supply-side reforms that promote the smooth flow of government orders can a successful economic transformation be achieved.

\section{REFERENCES}

[1] Andre K.Anundsen \& Eilev S.Jansen.Selfreinforcing Effects between Housing Prices and Credit[J].Journal of Housing Economics, 2013(18): 71-77.

[2] Liu Chuanzhe, Nie Xuefeng. An Empirical Analysis of China's Monetary Policy Passing Through RE Investment[J]. Statistics and Policy, 2006(3): 94-96.

[3] Ma Zhefeng, Yuan Hui. Empirical analysis and policy recommendations on the factors affecting the price of RE in China [J]. Modern Economy: Modern Property Next Edition, 2008 (9): 7-12.

[4] Luo Xiaoling, Hong Bo, Ma Shichang. Research on Influencing Factors of RE Price Based on VAR Model[J]. Journal of Central South University (Social Science Edition), 2012, 18(4): 1-7.

[5] Wen Chujiang. Research on the influence of money supply on the price of RE in China [D]. Guangdong University of Foreign Studies, 2013.

[6] Miao Qing. Theoretical and Empirical Research on China's Money Supply Affecting RE Prices[D]. Capital University of Economics and Business, 2018.

[7] Yuan Qingqing. Research on the influence of China's money supply on RE prices[D]. Shanxi University of Finance and Economics, 2018.

[8] Liang Yunfang, Gao Tiemei. An Empirical Analysis of Regional Differences in China's RE Price Fluctuations[J]. Economic Research, 2007(8): 133142.

[9] Xu Xiaotong. An Empirical Study on the Relationship between Bank Credit and RE Prices in China[J]. Industry and Technology Forum, 2018(01): 88-89.

[10] Liang Qi. An Empirical Test on the Difference of the Interaction between Monetary Policy, Stock Price and Housing Price[J]. Heilongjiang Finance, 2018(07): 62-66.

[11] Zhang Xiekui, Dai Xiaoling. Analysis of the relationship between China's high housing prices and financial risks - based on the VAR model [J]. Price Monthly, 2018(07):7-14. 